\title{
Brushing without brushing? A review of the efficacy of powered toothbrushes in noncontact biofilm removal
}

\section{Journal Article}

\section{Author(s):}

Schmidt, Julia C.; Zaugg, Christian; Weiger, Roland; Walter, Clemens

Publication date:

2013-04

Permanent link:

https://doi.org/10.3929/ethz-b-000065255

\section{Rights / license:}

In Copyright - Non-Commercial Use Permitted

\section{Originally published in:}

Clinical oral investigations 17(3), https://doi.org/10.1007/s00784-012-0836-8 


\title{
Brushing without brushing?-a review of the efficacy of powered toothbrushes in noncontact biofilm removal
}

\author{
Julia C. Schmidt • Christian Zaugg • Roland Weiger • \\ Clemens Walter
}

Received: 24 August 2011 / Accepted: 28 August 2012 /Published online: 23 September 2012

(C) Springer-Verlag 2012

\begin{abstract}
Objectives The aim of the present review was to analyze the impact of the hydrodynamic effects created by powered toothbrushes on biofilm removal in vitro.

Materials and methods A MEDLINE search was performed for publications published by 20 May 2012; this search was complemented by a manual search. The study selection, data preparation, and validity assessment were conducted by two reviewers.

Results Sixteen studies were included. The studies differed with respect to the methods of biofilm formation and brushing protocols. Eighteen different powered toothbrush models were evaluated. Toothbrushes with side-to-side action demonstrated biofilm removal without direct bristle contact to biofilms ranging from 38 to $99 \%$. Most studies found biofilm removal exceeding $50 \%$. Biofilm reduction using multidimensional toothbrushes was significantly lower than by those with the side-to-side mode. Detachment forces due to hydrodynamic phenomena, passing air-liquid interfaces, and acoustic energy transfer were suggested to cause reduction of the biofilm.
\end{abstract}

J. C. Schmidt $\cdot$ R. Weiger $\cdot$ C. Walter $(\bowtie)$

Department of Periodontology, Cariology and Endodontology, University of Basel,

Hebelstrasse 3,

4056 Basel, Switzerland

e-mail: clemens.walter@unibas.ch

C. Zaugg

Department of Physics, Institute for Quantum Electronics,

ETH Zürich,

Wolfgang-Pauli-Strasse 16,

8093 Zürich, Switzerland

C. Walter

Department of Oral Surgery, School of Dentistry,

University of Birmingham,

Birmingham, UK
Conclusion Noncontact biofilm reduction was obtained by the hydrodynamic effects of some powered toothbrushes in vitro.

Clinical relevance Powered toothbrushes may have the potential to simplify self-performed oral hygiene. However, additional beneficial effects of higher amounts of noncontact biofilm removal in vitro have not been shown clinically, yet.

Keywords Powered toothbrush · Biofilm $\cdot$ Hydrodynamic effect $\cdot$ Oral hygiene $\cdot$ Preventive dentistry

\section{Introduction}

Periodontitis is a multifactorial disease caused by infection with pathogenic bacteria organized in a biofilm. A biofilm is a complex microbial structure on a solid wet surface protecting the microorganisms from the host's immune system and therapeutic measures, including mouth rinsing with antiseptics or antibiotics. Mechanical means are likely to be more predictable in biofilm removal but may still leave biofilm behind [1].

Removal of the supra- and subgingival biofilm is, therefore, a main concern of both preventive and therapeutic measures. Optimal oral hygiene performed by the patient is an important goal of periodontal therapy to establish periodontal health in the long term [2].

A major problem related to self-performed oral hygiene is the cleaning of the interdental areas [3]. While different methods exist, including sticks, dental floss, and interdental brushes, the use of interdental brushes seems currently to be the most efficient method [4-9]. Noncompliance with interdental hygiene measures, however, is a key problem in selfperformed oral hygiene [10]. Inadequate compliance in turn is associated with progression of periodontal diseases 
[11-13]. Time spent on oral hygiene as well as the use of interdental brushes were negatively correlated with further tooth loss in treated periodontitis patients [14].

Powered toothbrushes have been developed to improve and facilitate oral hygiene $[15,16]$. Various toothbrush modes of action, including multidimensional and side-toside action, exist and were classified in two recent systematic Cochrane reviews [17, 18].

Bristle motion at a high frequency may generate turbulent fluid flows in the oral cavity. The fluid flow causes hydrodynamic forces in terms of wall shear forces acting parallel to a surface $[19,20]$. The amount of entrained air bubbles correlates with increasing fluid motions. The passage of air bubbles along a substratum creates thermodynamic surface tension forces and turbulent flow depending on the gas fraction, the velocity, and the diameter of the bubbles entrained [21-24]. The vibration of toothbrush bristles may further enable energy transfer in terms of sound pressure waves [25]. In addition, the acoustic energy is thought to increase shear forces due to an oscillation of entrapped air bubbles [26]. The interaction of these effects created by powered toothbrushes is suggested to remove biofilms without bristle contact [27].

The aim of the present review was to evaluate the current evidence regarding the efficacy of powered toothbrushes in noncontact biofilm removal in in vitro studies.

\section{Methods}

Outcome variables

The primary outcome variable was the quantification of biofilm removal following application of a powered toothbrush without contact to the surface, i.e., to the biofilm, in vitro. The secondary outcome variables considered the viability of biofilm-associated bacteria and hydrodynamic phenomena occurring during noncontact application.

\section{Literature search}

A MEDLINE search (PubMed) of resources published prior to 20 May 2012 was conducted using the validated keywords "powered" and "toothbrush" or "powered" and "toothbrushes" or "electric" and "toothbrush" or "electric" and "toothbrushes" or "sonic" and "toothbrush" or "sonic" and "toothbrushes" or "ultrasonic" and "toothbrush" or "ultrasonic" and "toothbrushes." Further databases beside MEDLINE were not reviewed. Any relevant work published in the English language and presenting pertinent information about the described outcome variables was considered for inclusion in the review. Moreover, the references of studies examined for inclusion were thoroughly analyzed searching for further studies. However, there may be other evidence but for convenience the search was limited to English publications and the grey literature was not actively searched.

Validity assessment

One reviewer (J. S.) screened the abstracts of the search results for compliance with the inclusion criteria. The full texts of studies with questionable potential for inclusion after the abstracts were read were further analyzed. A second reviewer (C. W.) reconsidered included studies as well as exclusions. Disagreements were clarified by discussion between the two reviewers.

\section{Results}

Study characteristics

The combinations of the search terms resulted in a list of 403 titles. Abstracts were first screened to identify possible relevant publications. Of these 403 initial titles, 382 were excluded following evaluation of the abstracts. The causes of exclusion were as follows:

- Review articles (72 publications),

- Clinical studies (254 publications),

- Animal studies (five publications),

- Comments (five puplications),

- Case reports (three publications),

- In vitro studies without data on noncontact biofilm removal (43 publications).

Full-text analysis was performed on the remaining 21 publications [15, 22, 25, 26, 28-44]. Twelve publications were further excluded for the following reasons:

- No noncontact brushing [32]

- Use of nonmicrobial substitute for biofilm [29, 31, 33, $36,38]$

- Use of planktonic bacteria [34, 35]

- No quantification of biofilm removal [30]

- No powered toothbrushes $[22,26]$

- Review article [15]

Finally, a total of nine articles from the electronic search of the MEDLINE database were included [25, 28, 37, 39-44]. Seven additional publications were identified by screening the references of the studies evaluated for inclusion [27, 45-50] (Fig. 1). Finally, 16 studies were integrated in the present review. 
Fig. 1 Selection process of the studies included

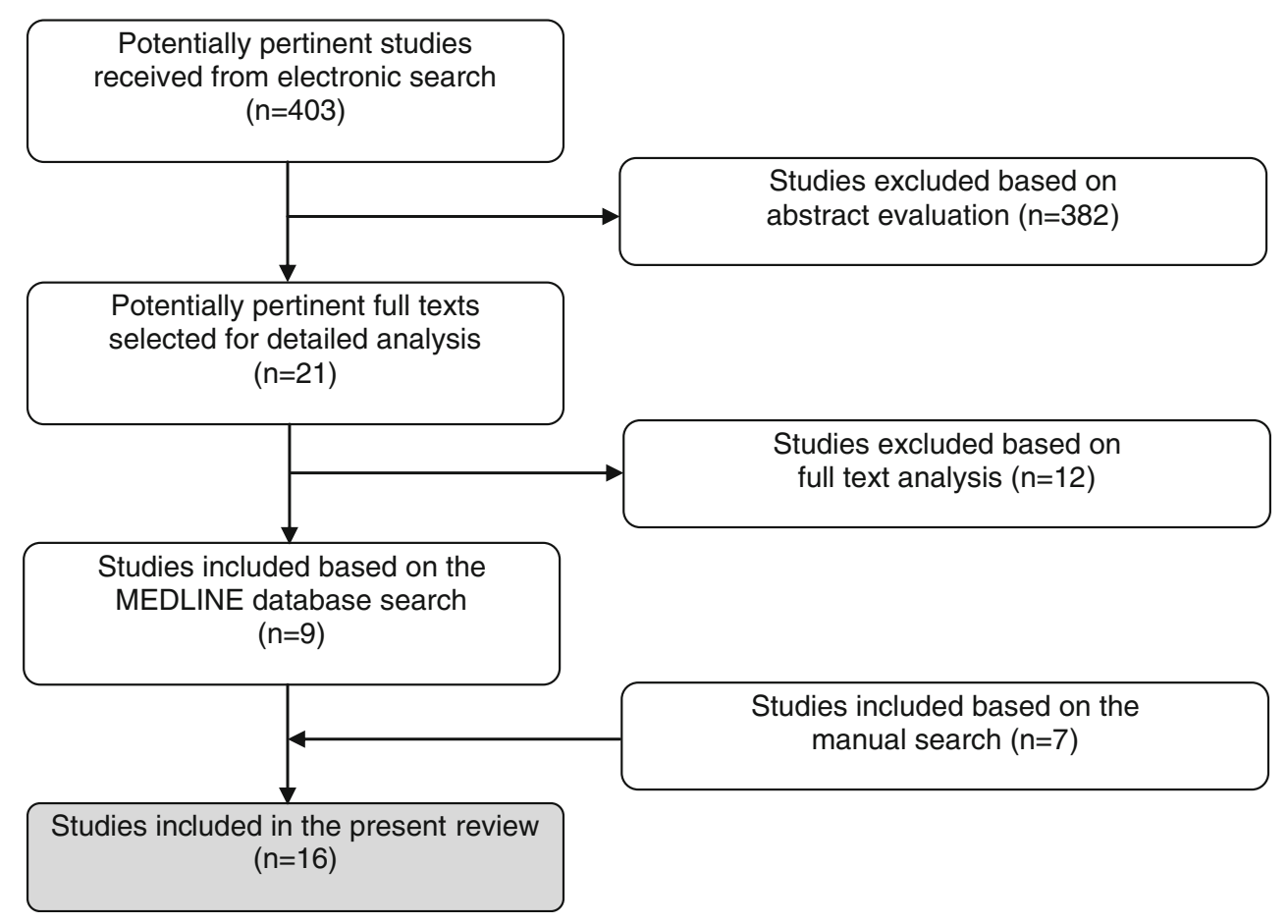

Analysis of the included studies

\section{Microbial aspects and biofilm formation}

Substratum Synthetics and substrates derived from animals or humans were utilized for bacterial adhesion and biofilm formation. Titan [45], glass and quartz [25, 27, 44, 46, 49], hydroxyapatite [28, 40-43, 47], bovine enamel sections [48], and human enamel sections from noncarious molars $[37,39]$ were used in the experiments (Table 1).

Bacteria The biofilm formation was conducted in vitro [25, $27,28,44,46,48,49]$, in vivo [37, 39] and ex vivo [40-43, 47]. Whereas the identity of bacteria and their applied concentrations in in vitro biofilms were known, these parameters were not precisely defined in in vivo and ex vivo biofilms.

In vitro studies primarily formed monospecies biofilms using different Streptococcus mutans strains (Ingbritt, UA 159, ATCC 700610, OSP 236, and NS) [27, 28, 44, 48, 50]. The bacteria used in monospecies biofilms were Porphyromonas gingivalis (ATCC 33277), Actinomyces naeslundii (T14V), Streptococcus oralis (J22), Lactobacillus acidophilus (DSP 211), Streptococcus salivarius (DSP 248), and Veillonella alcalescens (DSP 203) [48].

In vitro dual-species biofilms were created by sequential inoculation of $A$. naeslundii (T14V) and $S$. oralis (J22) or $A$. naeslundii (T14V) and Streptococcus sanguis (PK 1889) [25, 46, 49].

Additionally, multispecies biofilms were formed, using human whole saliva as the inoculum $[40-43,47]$ in an ex vivo model. Saliva samples were collected from 10 healthy volunteers.

In contrast, Stanford et al. used biofilms formed in vivo [37, 39]. All biofilm samples were obtained from two probands who continuously wore a palatal prosthesis with fixed enamel sections overnight.

Model biofilm system The (acquired) pellicle is important for in vitro and ex vivo biofilms. The use of pooled human saliva is documented [25, 46, 49]. Human saliva was collected from ten healthy volunteers and incubated with the substratum for $16 \mathrm{~h}$. Additionally, saliva was supplementally added to the circulating bacterial suspension.

The simultaneous flow of saliva and inoculum is described by Hope et al. [40-43]. Briefly, the flow of human saliva containing oral bacteria started concurrently with artificial saliva and was continued for 8 days. Artificial saliva consisted of hog gastric mucin without urea. Another type of artificial saliva used for pellicle formation comprised sterile $2.5 \%$ bovine mucin $[28,48]$ and $10 \%$ fetal calf serum [45]. The incubation periods lasted $0.5,12$, and $1 \mathrm{~h}$. A few studies failed to include pellicle formation in their biofilm model [27, 44].

In vitro and ex vivo model biofilm systems may be differentiated into static and dynamic systems. Static biofilms were established in multiwell plates. Exclusively, monospecies biofilms were developed $[45,48]$. Incubation periods varied from 1 to $48 \mathrm{~h}$. Dynamic biofilm systems imitate the flow rate and shear forces caused by the dynamic flow of saliva in the oral cavity. 


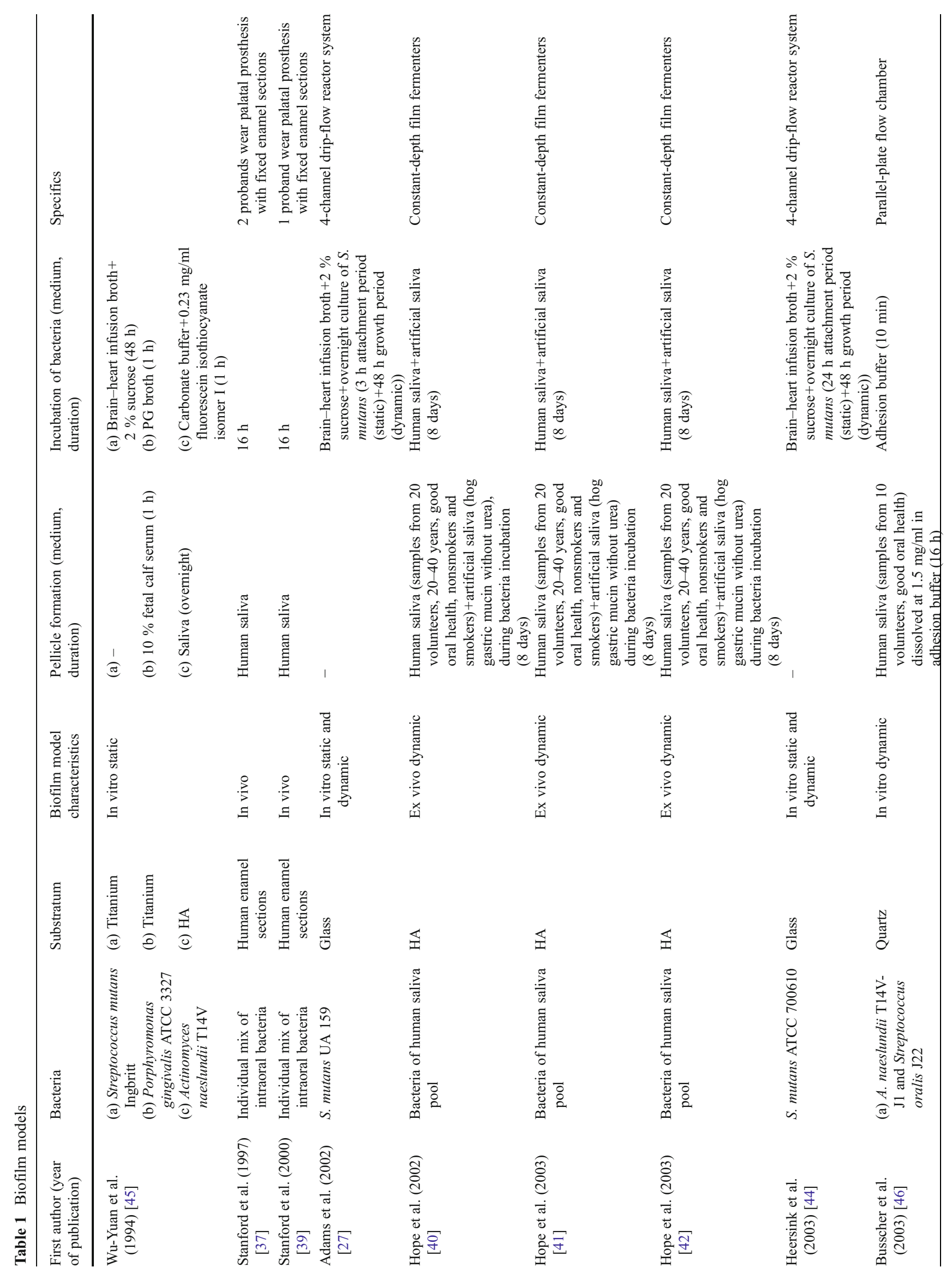




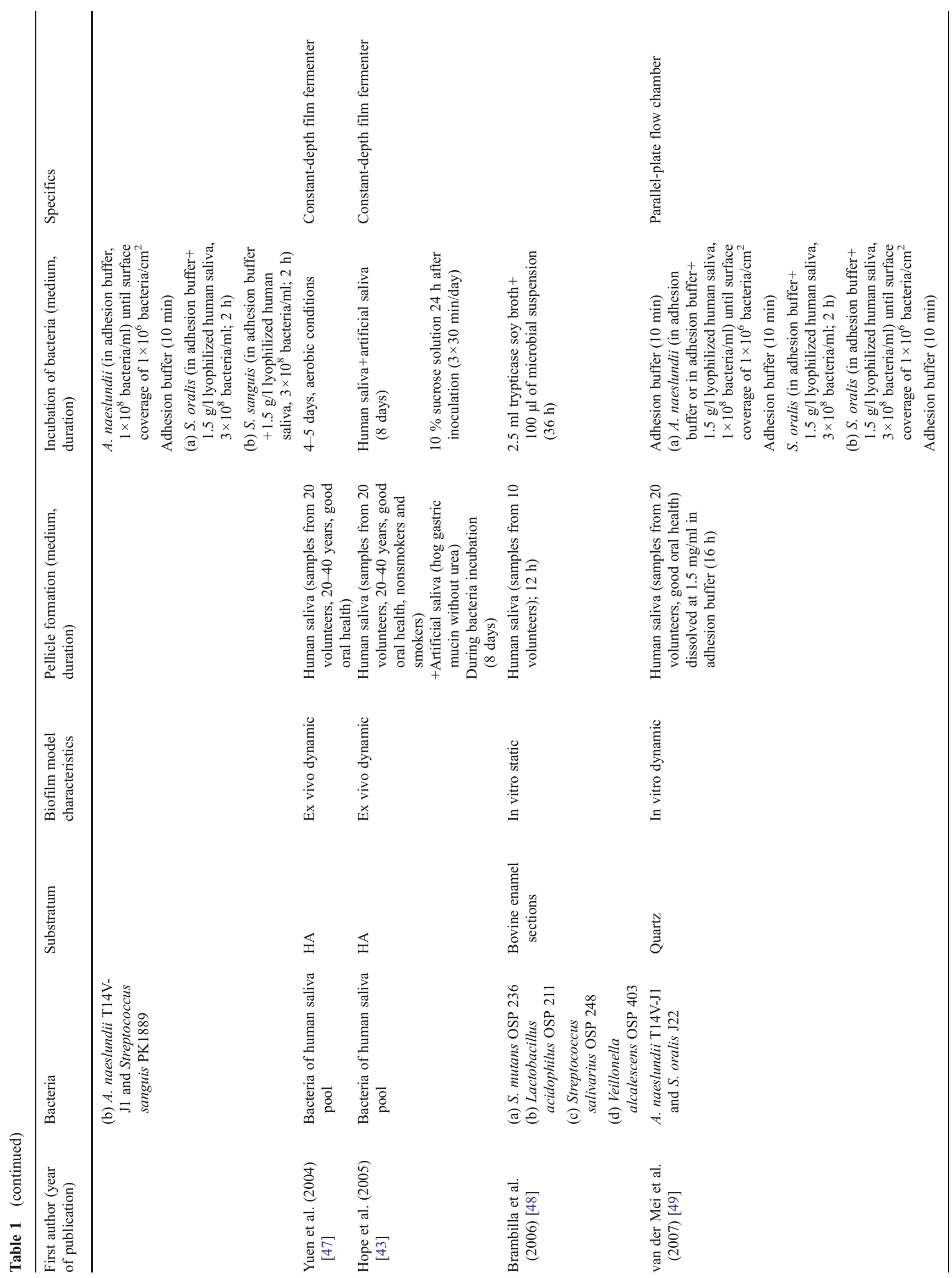




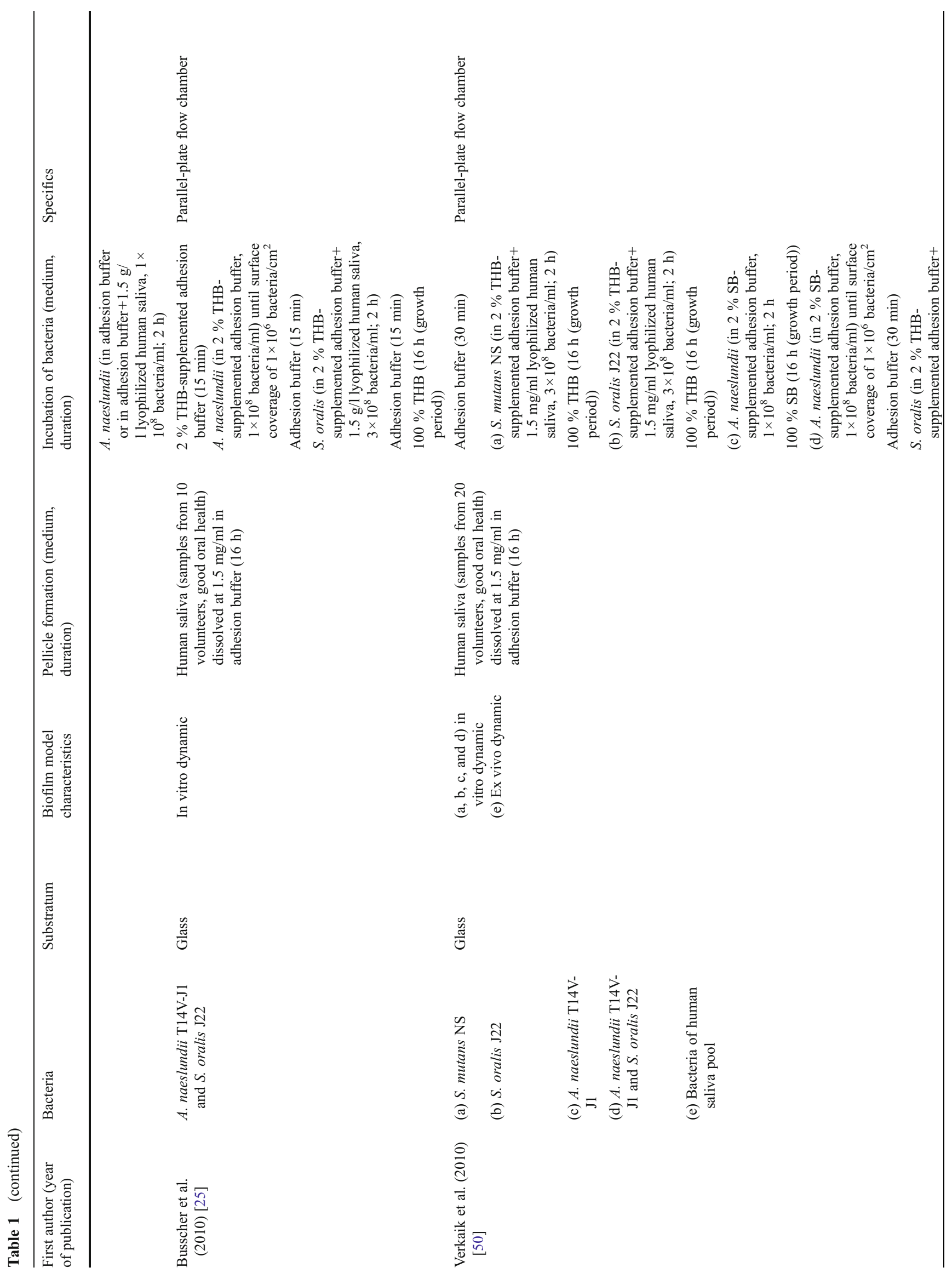


The formation of multispecies biofilms was performed by means of dynamic systems; the apparatus selected varied from study to study. These included the parallel-plate flow chamber [25, 46, 49], the drip-flow system [27, 44], and the constant-depth film fermenter [40-43, 47]. These devices allow the continuous flow of a bacterial suspension and a nutrient medium. The duration of biofilm formation varied from $3 \mathrm{~h}$ to 8 days.

\section{Brushing protocols}

Toothbrushes Wu-Yuan et al. were the first to analyze the influence of a toothbrush with side-to-side action on biofilm reduction by noncontact brushing [45]. Side-to-side toothbrushes were either solely tested [39, 42, 44-46, 48] or compared with powered toothbrushes presenting other modes of action. Comparison with multidimensional toothbrushes was predominant $[25,27,28,40,41,43,47,49$, 50]. Stanford et al. investigated a counter oscillation and a side-to-side toothbrush [37]. The most extensive study of powered toothbrushes in terms of different modes was performed by Buscher et al. [25]. The efficacy of a toothbrush with ultrasonic action in comparison to a side-to-side and a multidimensional toothbrush was also studied [28] (Table 2).

Toothbrush apparatus The angle of the toothbrush bristles toward the biofilm was $90^{\circ}$ in most studies. The bristles were not in contact with any solid surface $[25,28,37,39$, 44, 46, 48, 49]. Apart from the orientation of the bristles, there was additional movement of the toothbrush in some studies [27, 46, 49].

In addition, an interproximal model was developed to simulate the exposure of interproximal biofilm to powered brushing from the buccal surface [27, 40-43, 47]. The bristles were in direct contact with an artificial tooth surface. Hope et al. quantified the vertical and horizontal load of the bristles to be $62 \pm 5 \mathrm{~g}$ for the side-to-side toothbrushes in accordance to the manufacturers' recommendations. The horizontal load of the multidimensional toothbrushes amounted to $150 \pm 10 \mathrm{~g}$, while the vertical load was minimal [40-43]. The angle of the toothbrush head to teeth was $45^{\circ}$ and $40^{\circ}$ for side-to-side toothbrushes and $90^{\circ}$ for multidimensional toothbrushes, respectively.

Medium The analysis of biofilm removal by hydrodynamic phenomena requires a liquid in which to immerse the toothbrush bristles and to imitate the mix of saliva, water, and toothpaste in the oral cavity.

For this purpose, phosphate-buffered saline solution [37, 40-43], phosphate-buffered saline solution supplemented with artificial saliva (i.e., hog gastric mucin) [37, 40-43], adhesion buffer [25, 46, 49], sterile Ringer solution [27], 


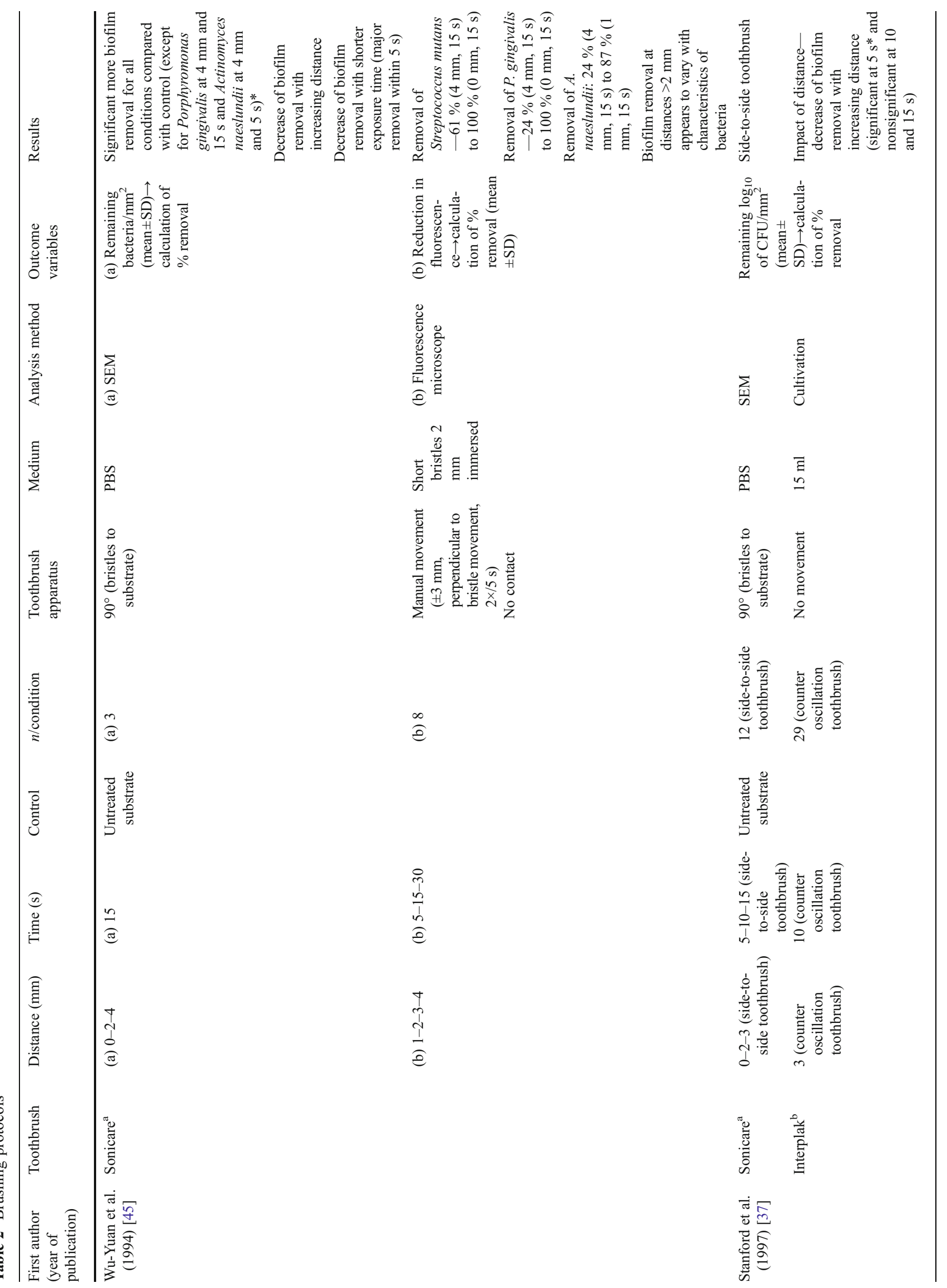




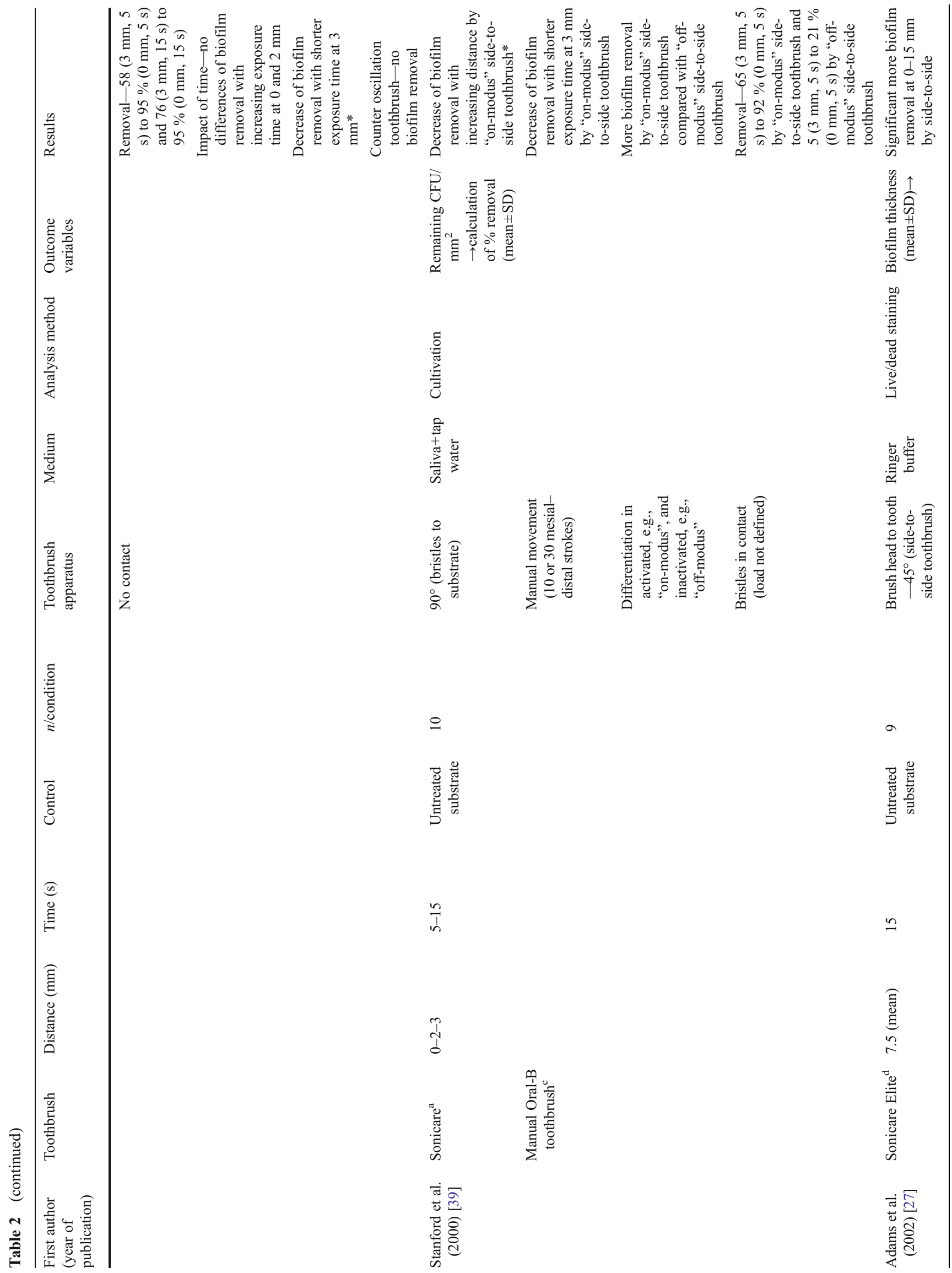




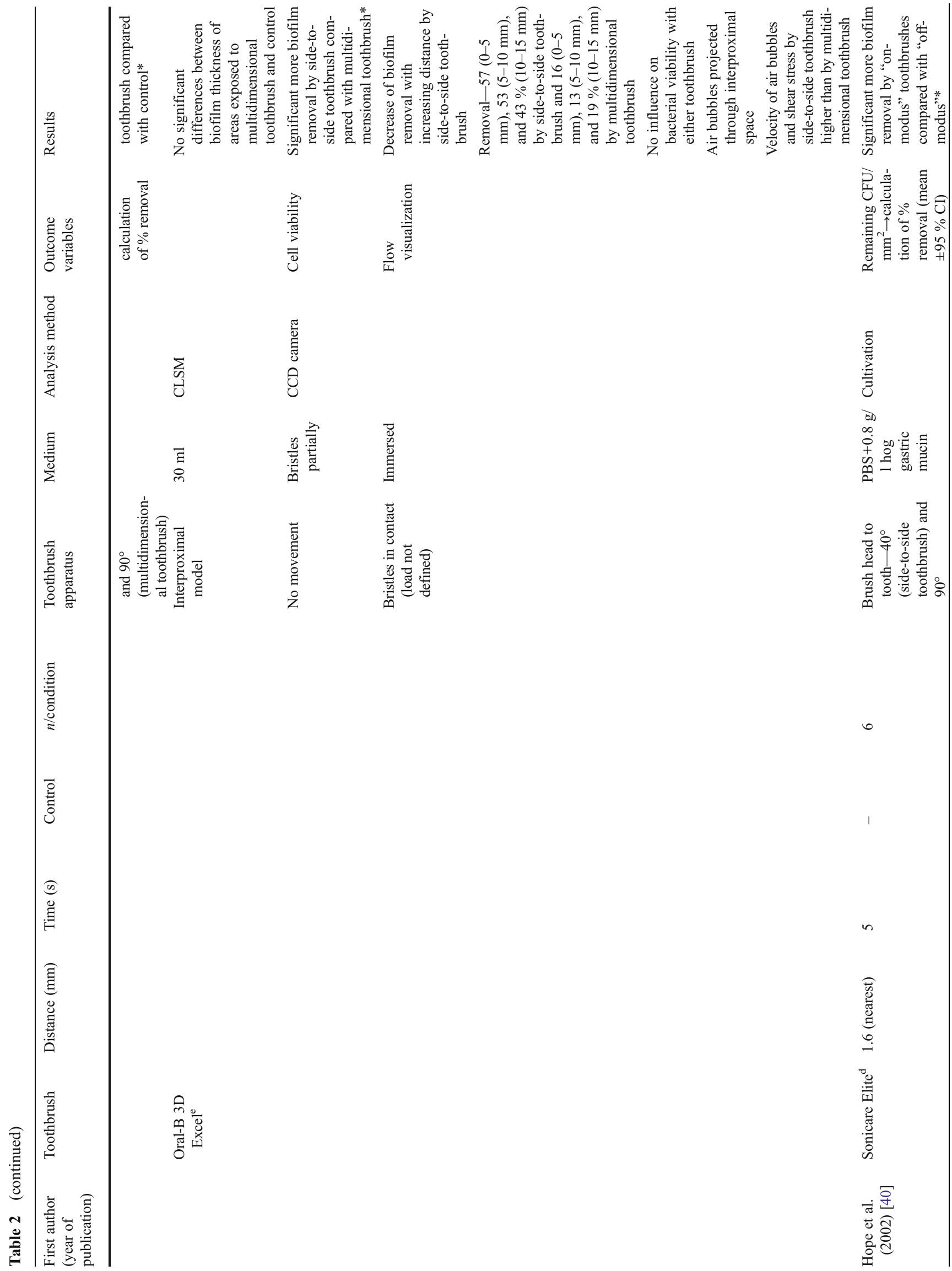




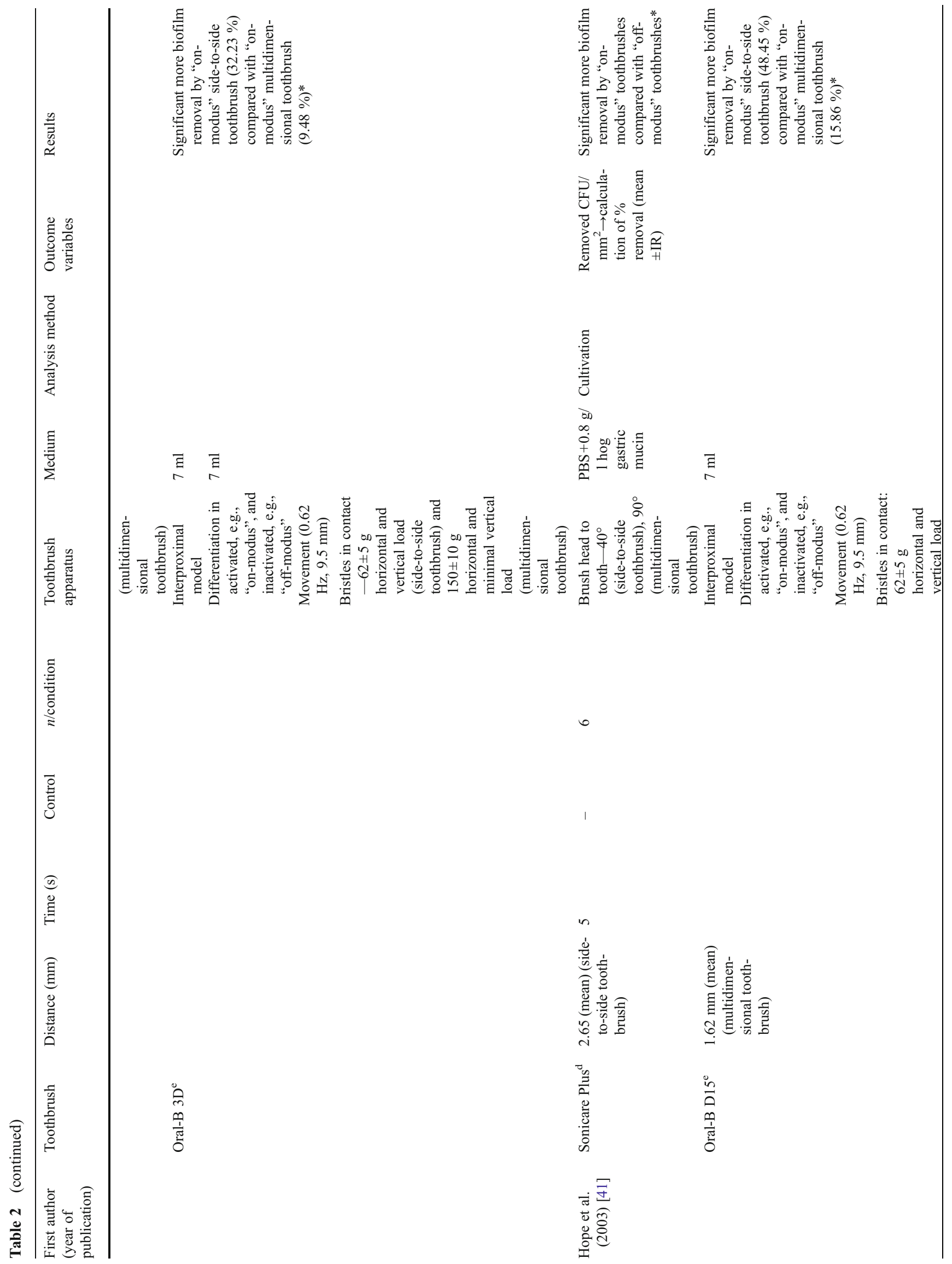




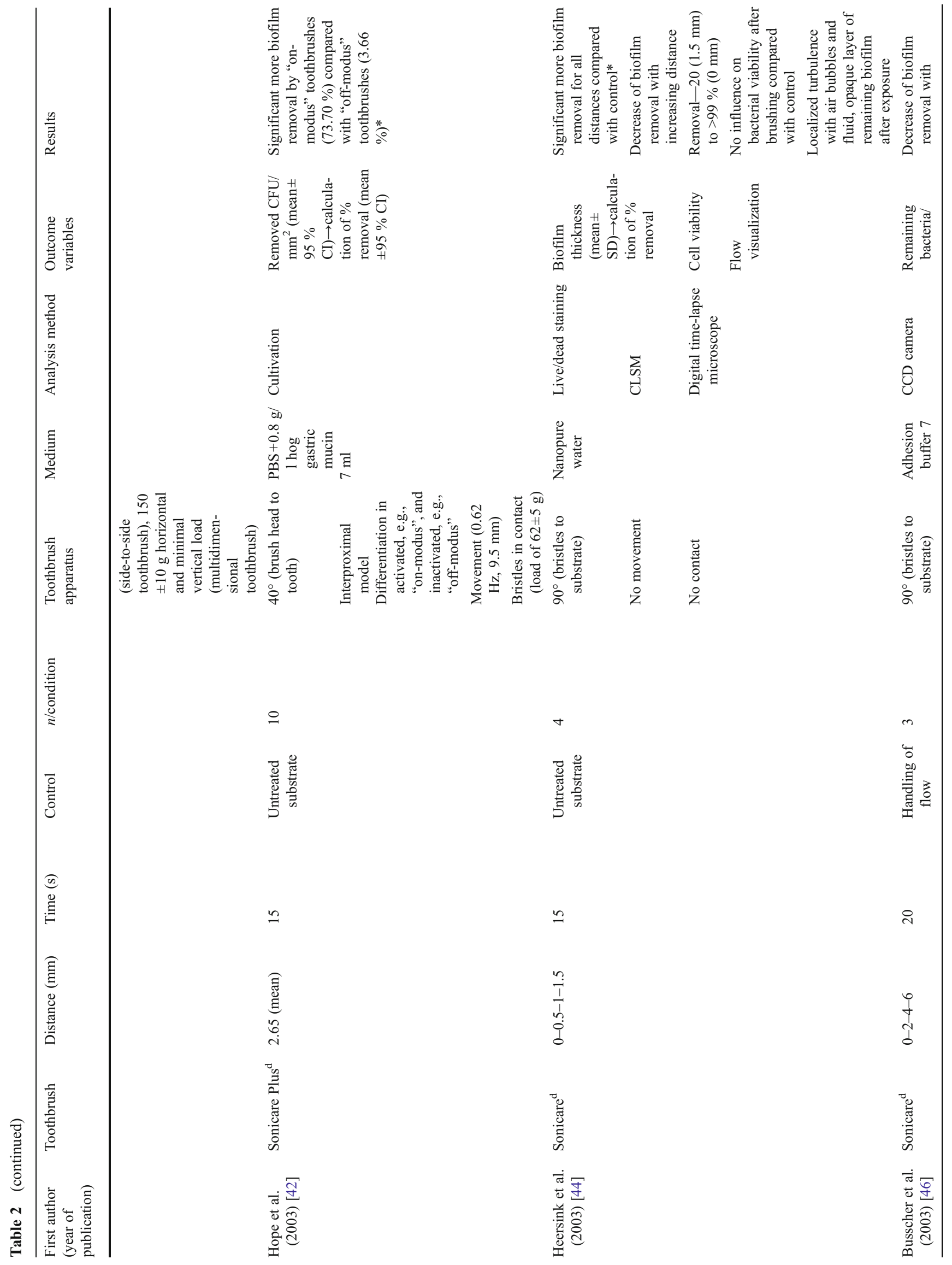




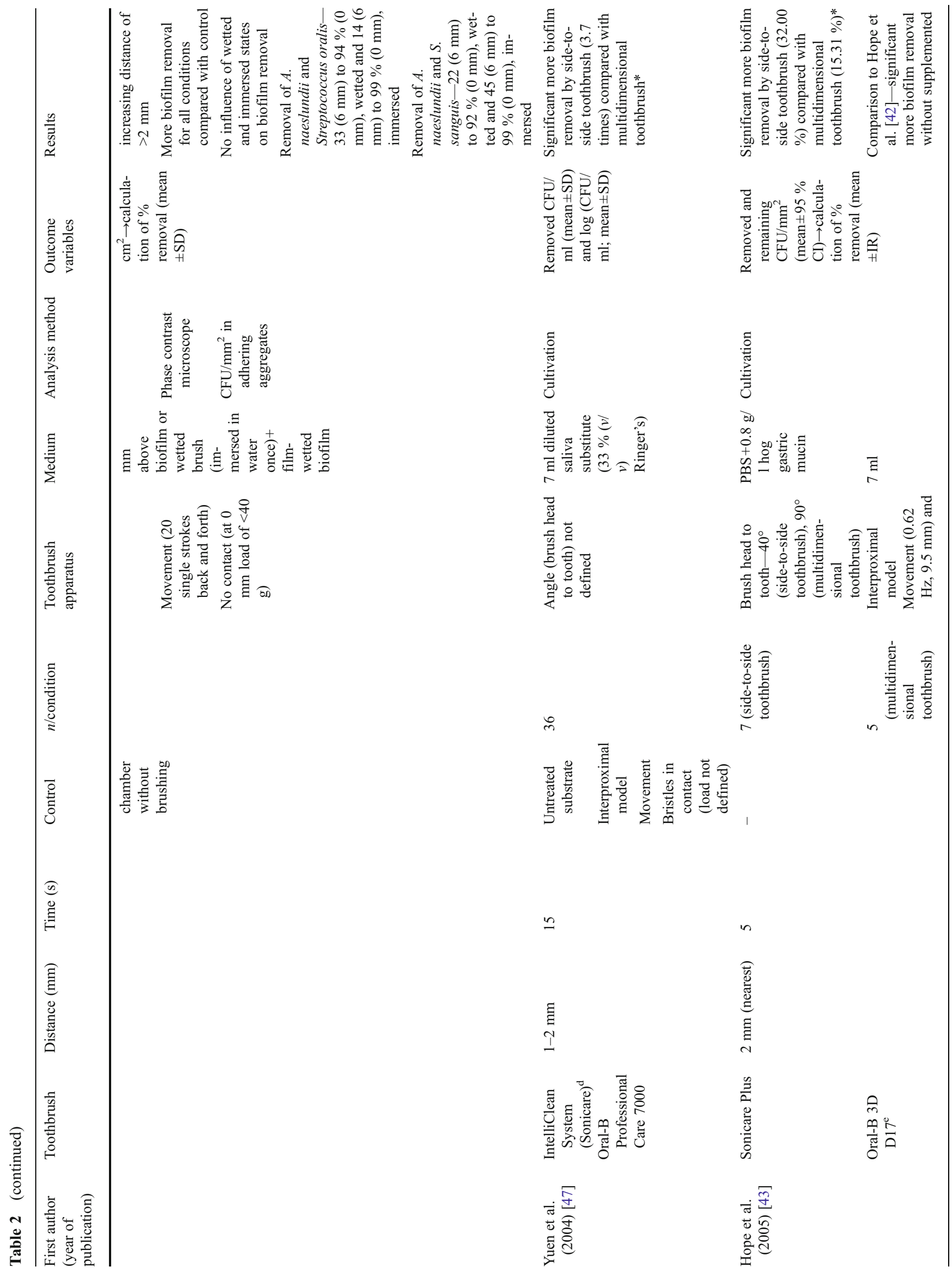




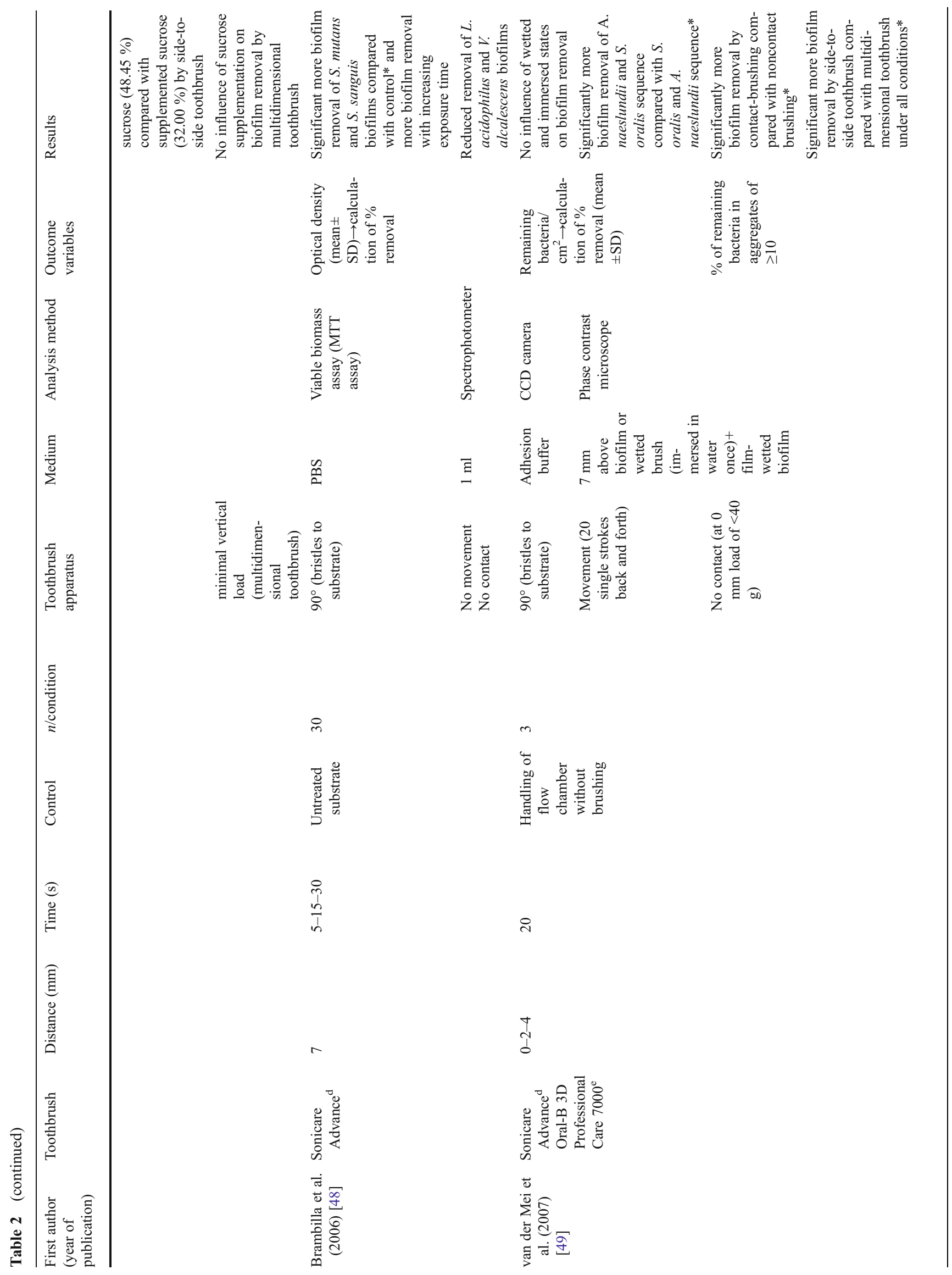




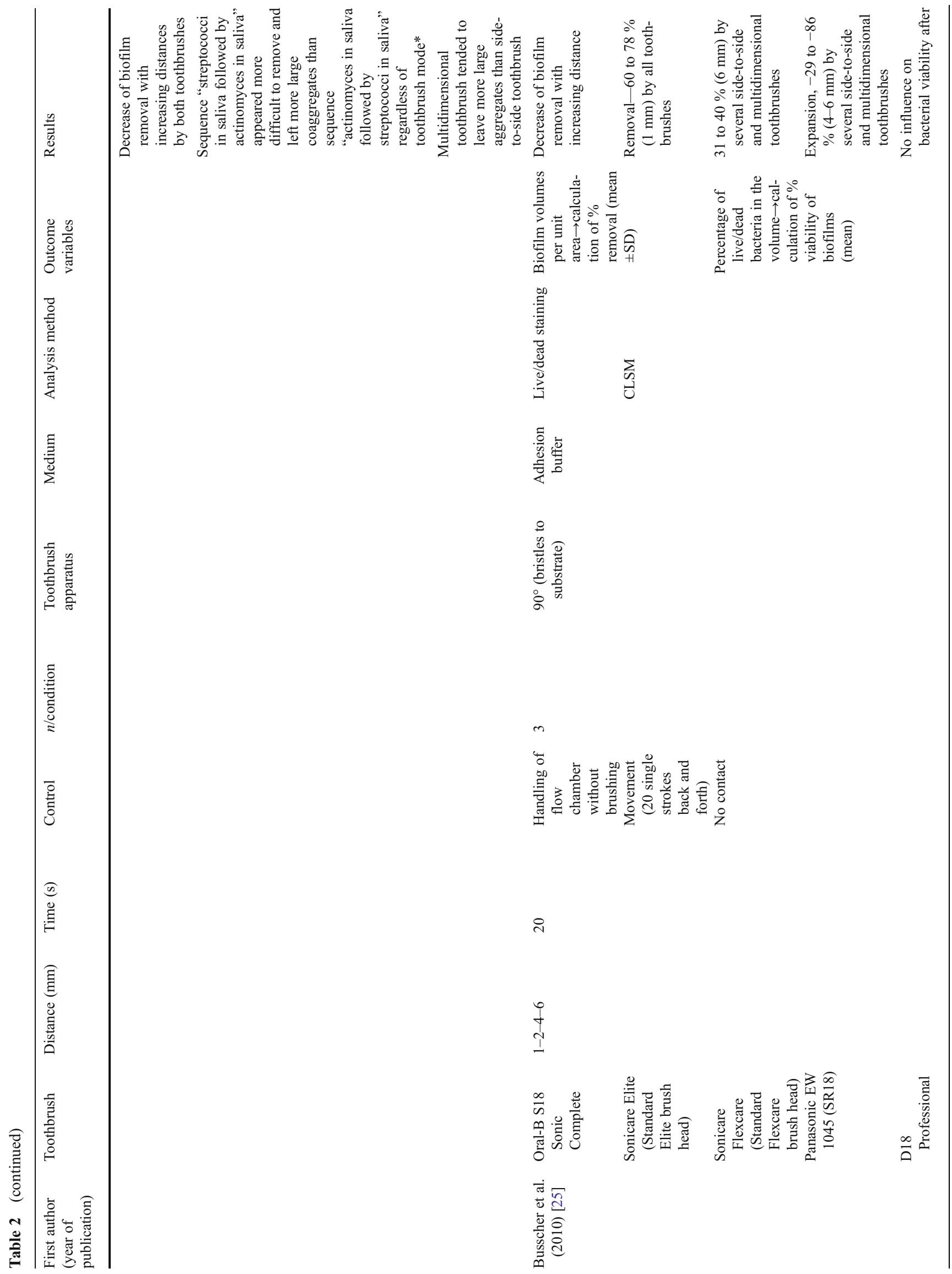




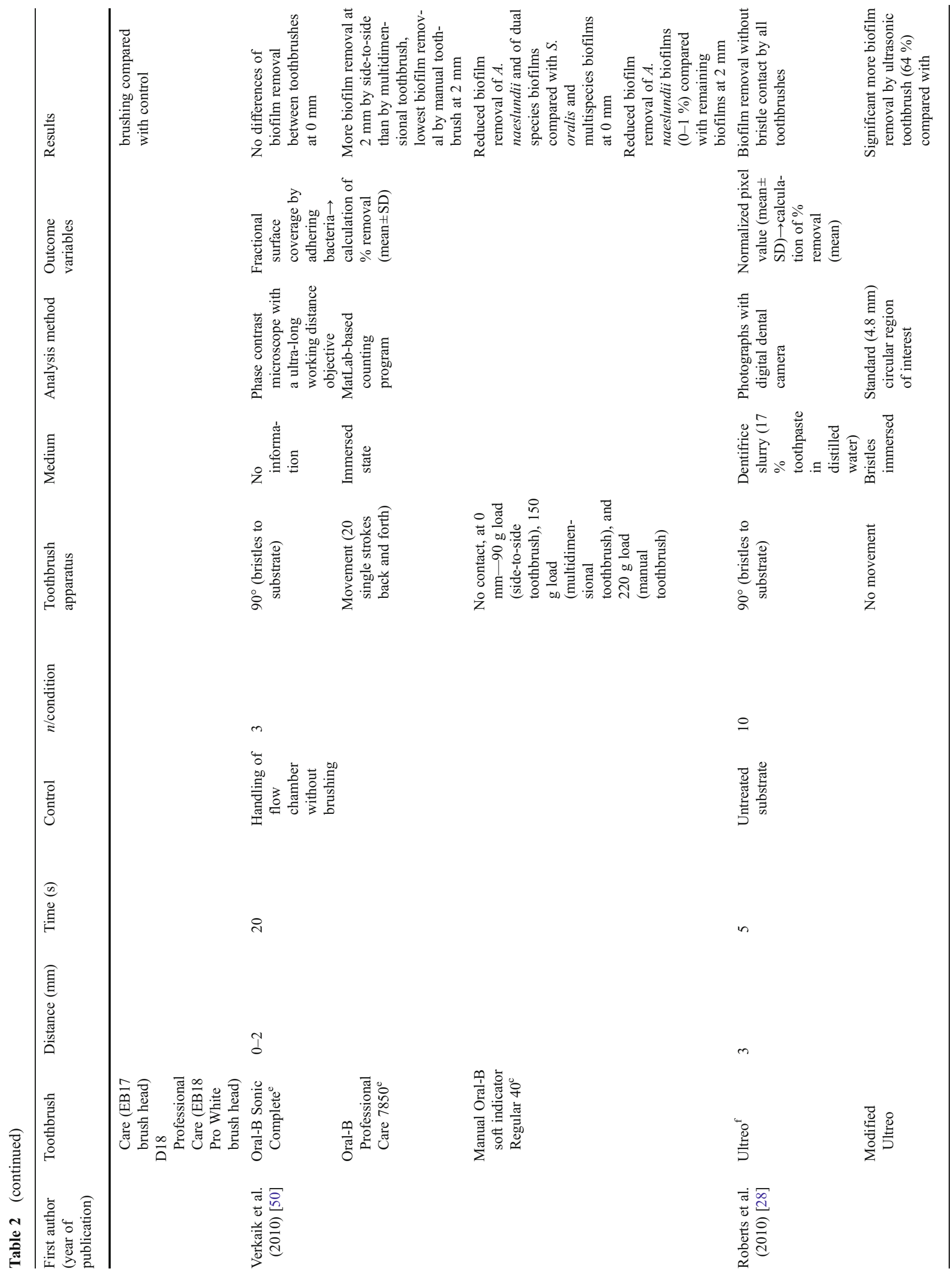




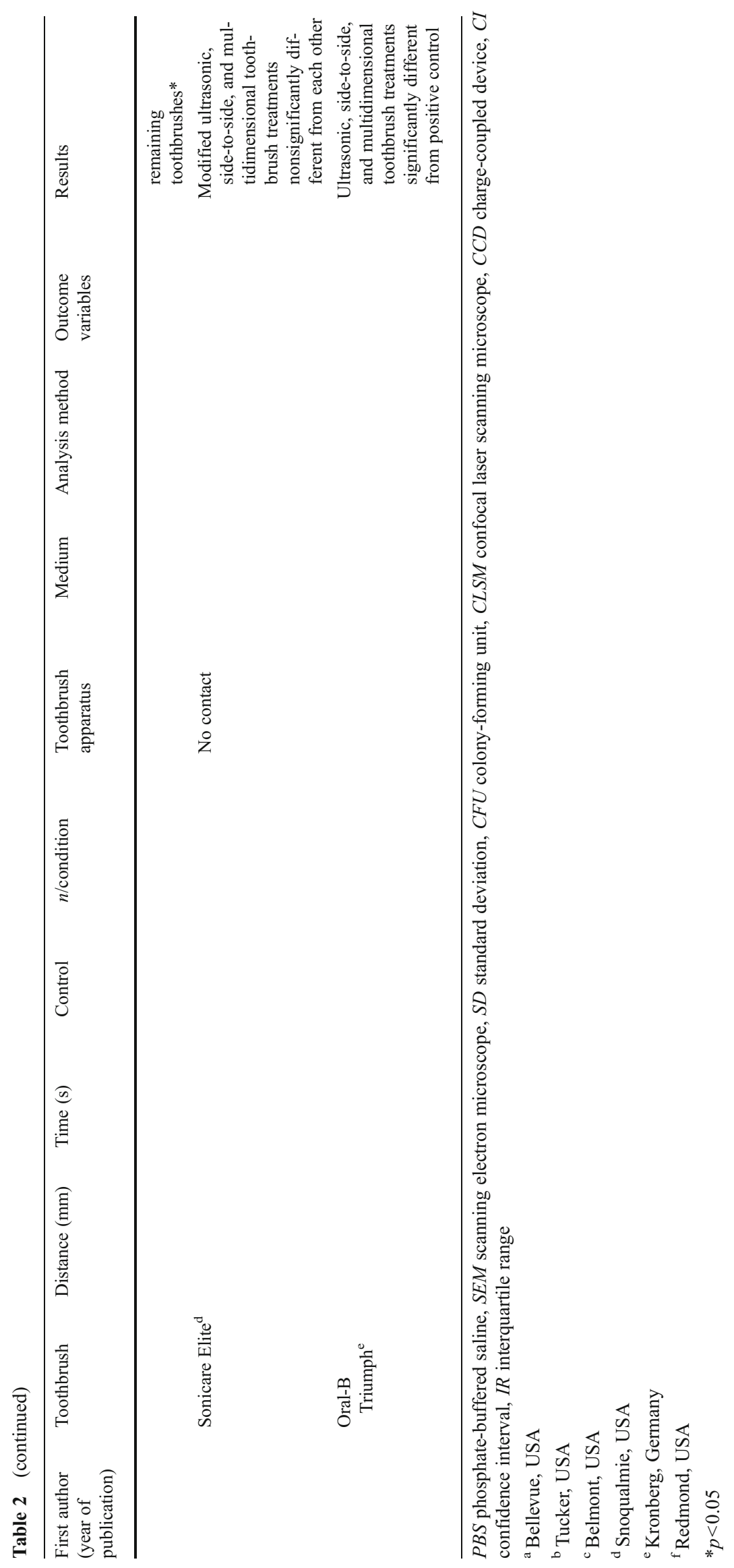


nanopure water [44], diluted saliva substitute [47], and a dentifrice slurry consisting of $17 \%$ toothpaste in distilled water [28] were employed.

Despite the different liquid volumes, the toothbrush bristles were always partially immersed. In addition, biofilm removal was studied using a wetted substratum and a wetted toothbrush $[46,49]$.

Exposure time and distance To evaluate the influence of varying times and distances on biofilm removal by noncontact brushing, exposure time and distance were analyzed. Alteration of the distance along with a constant exposure time elucidated the influence of different distances on biofilm removal. The distances varied from 0 to $6 \mathrm{~mm}$ with an exposure time of 15 or $20 \mathrm{~s}$ [25, 44, 46, 49].

A few studies analyzed the alteration of both parameters to assess the impact of exposure time as well as of distance $[37,39]$. Some studies, however, did not analyze either exposure time or distance [27, 28, 40-43, 47]. The distance between bristles and biofilm was not uniform because of the interproximal model [27, 40-43, 47]. The mean separation between bristles and biofilm was $2.65 \mathrm{~mm}$. The exposure time of $5 \mathrm{~s}$ was arrived at by considering the average time of brushing in relation to the number of teeth $[27,28,40-43]$. Furthermore, an exposure time of $15 \mathrm{~s}$ was used [27, 42, 47].

\section{Results}

Toothbrush efficacy: biofilm removal Biofilm removal was quantified by microscopic analyses, including the use of a confocal laser scanning microscope combined with live/ dead staining [25, 27, 44], a scanning electron microscope [45], a phase-contrast microscope connected to a chargecoupled device (CCD) camera [46, 49], and a fluorescence microscope [45]. The quantification of biofilm removal was further determined by viable count procedures [37, 40-43, 47], by means of a viable biomass assay combined with the measurement of optical densities [48], and by normalized pixel values on photographs [28] (Table 2).

The included studies consistently reported biofilm reduction by noncontact brushing of tested side-to-side, multidimensional and ultrasonic toothbrushes [25, 27, 28, 37, 39-50]. Side-to-side toothbrushes yielded significantly more biofilm removal than multidimensional brushes [27, 40, 41, 43, 47, 49, 50]. Biofilms were not reduced by counter oscillation toothbrushing [37].

Considering that a distance of $2 \mathrm{~mm}$ and an exposure time of 15 to $20 \mathrm{~s}$ were the most commonly parameters for examining side-to-side toothbrushes, there was a wide range, i.e., from 38 to $99 \%$, in the percentage of biofilm removed. Most studies, however, found $>50 \%$ biofilm removal by side-to-side toothbrushes $[25,46,49,50]$. In contrast, biofilm reduction by multidimensional toothbrushes was frequently $<50 \%[49,50]$. The percentage of biofilm removal at a 2-mm distance and after $5 \mathrm{~s}$ of exposure was reported as 74 [45] and $65 \%$ [37] by side-to-side action. Regarding the efficacy of side-to-side brushes in interproximal models with a mean distance of approximately $2 \mathrm{~mm}$ and an exposure time of $5 \mathrm{~s}$, there was biofilm removal of 32 [40, 43], 48 [41], and $74 \%$ [42]. In contrast, multidimensional toothbrushes achieved a biofilm reduction of 9 [40], 15 [43], and $16 \%$ [41] using the same interproximal model.

Some studies analyzed the influence of different exposure times on biofilm reduction by side-to-side toothbrushes $[37,39,48]$. At distances of 0,1 , and $2 \mathrm{~mm}$, there was no significant influence of exposure time (ranging from 5 to $30 \mathrm{~s}$ ). The majority of bacteria were removed within the first $5 \mathrm{~s}$ of exposure. At a distance of $\geq 3 \mathrm{~mm}$, however, exposures longer than $5 \mathrm{~s}$ had significantly greater effects [37, 39]. Brambilla et al. confirmed reduced biofilm removal at $7 \mathrm{~mm}$ after $5 \mathrm{~s}$ compared with exposures of 15 and $30 \mathrm{~s}$ [48].

Concerning the distance between toothbrush bristles and the biofilm, increasing distances almost invariably resulted in decreased biofilm removal by side-to-side and multidimensional toothbrushes $[25,27,37,44,46,49]$. Nevertheless, biofilm removal at a 4-mm distance and after 15 to $20 \mathrm{~s}$ fluctuated around $60 \%$ by side-to-side action in most studies $[27,46,49]$. Biofilm removal was also found at a distance of $6 \mathrm{~mm}[27,46]$. In contrast, Busscher et al. observed expansion of the biofilm after noncontact brushing for the first time [25]. At $4 \mathrm{~mm}$, biofilm expansion amounted to approximately $86 \%$ using a side-to-side toothbrush and to $29 \%$ by a multidimensional toothbrush. At $6 \mathrm{~mm}$, biofilms were expanded by $43 \%$ using another sideto-side toothbrush. Other tested powered toothbrushes yielded biofilm removal between 30 and $40 \%$ at a $6-\mathrm{mm}$ distance [25].

The reduction of biofilm by noncontact brushing seems to be dependent on the types of bacteria constituting the biofilm $[48,49]$. Removal of $S$. mutans and $S$. salivarius monospecies biofilms amounted to 41 and $30 \%$, respectively. In contrast, monospecies biofilms of L. acidophilus and $V$. alcalescens were not significantly reduced [48]. Moreover, biofilm removal differed among the sequences of inoculated bacteria [49]. Verkaik et al. compared the effect of noncontact brushing on monospecies, dual-species, and multispecies biofilms [50]. At a distance of $2 \mathrm{~mm}$ and after $20 \mathrm{~s}$ of exposure, monospecies biofilms of $A$. naeslundii (T14V) showed the least removal investigating both side-toside and multidimensional toothbrushes. In contrast, monospecies biofilms of $S$. mutans were completely removed by handling of the flow chamber. The greatest differences 
between side-to-side and multidimensional toothbrushes were observed for multispecies biofilms with side-to-side action showing more biofilm removal [50].

The state of immersion of the substratum and the bristles did not affect the percentage of biofilm removal [46, 49]. Biofilms with a thin liquid film were removed by a wetted toothbrush comparable with an immersed toothbrush. A completely dry powered toothbrush, however, removed significantly less bacteria.

Toothbrush efficacy: viability of biofilm-associated bacteria Studies using live/dead staining of biofilms reported no differences in the distribution of live and dead cells in tests and controls [27, 44]. The percentage viability of biofilms was $84 \%$ before and $82 \%$ after brushing [25].

Hydrodynamic phenomena A few studies examined the presence of hydrodynamic phenomena to explain biofilm removal by noncontact brushing. Adams et al. visualized the movement of fluid and air bubbles by means of a CCD camera [27]. They observed multiple air bubbles traveling through the interproximal area and calculated the velocity of air bubbles and the corresponding shear forces. The velocity of bubbles and the extent of shear forces did not differ significantly between side-to-side and multidimensional toothbrushes despite different biofilm removal efficacies. Using a digital timelapse microscope, Heersink et al. also described fluid turbulences in which air bubbles were seen [44].

The importance of fluid, either in terms of fluid or even just as droplets, was emphasized by Busscher et al. when comparing the efficacy of completely dry, wetted and immersed toothbrushes [46]. Busscher et al. further analyzed the energy transfer by acoustic pressure waves and correlated it to powered toothbrushes [25].

\section{Discussion}

The aim of the present review was to analyze the efficacy of powered toothbrushes in noncontact brushing. A total of 16 publications were included from the electronic search of the MEDLINE database and from a further manual search. Data were exclusively collected from in vitro studies.

Included studies were analyzed with regard to the technical and microbial aspects of the applied methods as well as in terms of quantitative biofilm removal, the viability of biofilm-associated bacteria and hydrodynamic phenomena.

The mode of action of powered toothbrushes was defined in two recent systematic reviews [17, 18]. A consensus exists that toothbrushes with side-to-side, multidimensional, and ultrasonic action enable biofilm removal by noncontact brushing although biofilms were not completely eliminated from surfaces $[25,27,28,37,39-50]$. Biofilm reduction was more pronounced by side-to-side toothbrushes than by multidimensional action [27, 40, 41, 43, 47, 49, 50]. However, an extrapolation of these findings to powered toothbrushes not analyzed in this review should be undertaken with care. A shift in the distribution of live and dead bacteria after noncontact brushing was not observed. The interplay of hydrodynamic action, passing air bubbles and acoustic energy transfer was associated with biofilm removal.

Therapy of periodontal diseases and the establishment of periodontal health in the long term require well-performed dental plaque removal by the patient on a daily basis. Noncompliance with oral hygiene measures, in particular with difficult to access areas, such as the interdental area, however, is observed frequently $[10,14]$. If powered toothbrushes are able to remove biofilms efficiently without bristle contact, they would probably simplify and consequently improve self-performed oral hygiene. However, up to now there is no proof that this will work in a clinical situation, as well.

When comparing the in vitro data from the included studies, differences in brushing protocols and biofilm formation need to be considered:

1. An important parameter is the strength of the in vitro biofilm. The adhesiveness of biofilms depends on the physical properties of the surface, such as roughness [51]. Irregularities of the tooth structure in terms of fissures and pits increase bacterial colonization and offer protection from shear forces. When using artificial substrates, such as glass and quartz $[27,46]$, the experimental results may be biased. The adhesion of salivary pellicle constituents and subsequently of adherent bacteria is presumably less than on tooth structures. Irrespective of physical and chemical differences with respect to enamel, titanium sections imitate implant surfaces [45]. The adhesiveness and thus the strength of biofilms is further dependent on the acquired salivary pellicle providing receptors for bacterial binding [52]. It is suggested that the strength of biofilms is less severe in methods evaluated without saliva for pellicle formation.

2. Bacteria have been identified adhering as early colonizers to tooth surfaces and preceding the attachment of late colonizers [53]. Both Actinomyces and Streptococcus species are considered to be early colonizers [54]. Using these bacteria in in vitro biofilms, adhesion to the salivary pellicle can be expected $[25,50]$. Gram-negative bacteria, such as $P$. gingivalis, become more prominent in the biofilm at a later stage. They prefer receptors on other oral bacteria forming coaggregates to those of the salivary pellicle. This finding needs to be considered when using these bacteria in in vitro monospecies biofilms [48].

3. In addition to adhesiveness, which depends on the substratum, the acquired pellicle and early microbial colonizers, 
the strength of oral biofilms depends also on cohesiveness [55]. Several factors may affect cohesiveness: bacteria involved in biofilm formation, the presence of exopolysaccharides and environmental factors such as hydrodynamics and nutrient concentration. Bacteria increase the strength of a biofilm by coaggregation to a defined set of partners. Using A. naeslundii and $S$. oralis in dual-species biofilms, coaggregation of these bacteria is expected [56]. Coaggregation of bacteria is also assumed in ex vivo biofilms derived from human whole saliva $[40-43,47]$ as well as in in vivo biofilms [37, 39].

4. The presence of exopolysaccharides strengthens the biofilm [55, 57]. The amount of exopolysaccharides rises with increasing time and nutrient concentration. Accordingly, the adhesion and growth curves of bacteria in biofilm model systems need to be considered.

5. Hydrodynamic conditions during growth influence biofilm strength. Increased hydrodynamic shear decreased the biofilm strength and changed the architecture from uniform carpet like to more fluffy with increased thickness [57]. Some model biofilm systems considered the impact of hydrodynamics. The parallel-plate flow chamber allows for the circulation of bacteria and nutrients by means of hydrodynamic pressure at a wall shear rate corresponding to physiological conditions [25, 46, 49]. Whereas adhesion of bacteria in a drip-flow reactor system occurs statically, nutrients subsequently flow during a 48-h growth period [27, 44]. In contrast, the strength of biofilms grown in static systems without shear differ significantly from that observed in natural intraoral biofilms $[50,58]$.

6. Brushing protocols as well as toothbrush apparatuses differed among the in vitro studies included. Basically, toothbrushes can be mounted either without any bristle contact to a solid surface or in an interproximal model with bristle contact with artificial teeth. Evidence exists that bristle load influences the deformation of bristles as well as the efficacy of brushing [32, 59]. Moreover, in interproximal models, the fluid is impelled into the interproximal space, generating high shear forces [25]. Without this narrow set-up, fluid and energy transfer would spread across a larger area and in several directions. It is suggested that these arrangements affect biofilm removal in interdental spaces [25].

7. Most liquids used to transfer hydrodynamic phenomena, such as phosphate-buffered saline, show lower viscosities and lower colloid content than the mix of saliva, toothpaste and water in vivo. The addition of artificial or human saliva, however, reflects the salivary component [28, 40-43, 47], whereas supplementation with toothpaste imitates the dentifrice slurry [28, 40-43]. It is suggested that different liquid viscosities and volumes influence the bristle velocity, the fluid flow, the formation of air bubbles and the shear forces [59]. Otherwise, the use of toothpaste in brushing protocols would probably distort toothbrush efficacy by affecting the chemical antibacterial efficacy [60]

8. The time spent for an oral hygiene session is on average 2 to $3 \mathrm{~min}[61,62]$. This means that the time available for cleaning a tooth surface interproximal space amounts to 4 to $6 \mathrm{~s}(2 \min =120 \mathrm{~s}, 120 \mathrm{~s} / 28$ teeth= $4.28 \mathrm{~s} ; 3 \mathrm{~min}=180 \mathrm{~s}, 180 \mathrm{~s} / 28$ teeth $=6.43 \mathrm{~s}$ ). Therefore, exposure times of $5 \mathrm{~s}$ seem to be realistic and comparable to in vivo brushing times [40-43]. Exposure of the biofilm during a period of $20 \mathrm{~s}$, however, would imply an overall brushing time far from clinical reality that may be of less clinical relevance.

To what extent the mechanisms of hydrodynamic action, passing air-liquid interfaces, and acoustic energy transfer contribute to the noncontact biofilm removal by powered toothbrushes was not separately investigated.

Hydrodynamic fluid shear forces were estimated by Adams and coworkers to amount approximately $0.9 \mathrm{~Pa}$ for the side-to-side toothbrush and 0.5 Pa for the multidimensional toothbrush [27]. In an aqueous solution, these values would correspond to fluid shear rates of about 0.9 and $0.5 \mathrm{~s}^{-1}$. For bacterial detachment from surfaces, however, shear rates of at least more than $10,000 \mathrm{~s}^{-1}$ due to increased fluid flow were suggested to be essential. The efficacy of the hydrodynamic forces in bacterial reduction depends on the cell surface hydrophobicity of bacteria [19]. The transition of a laminar in a turbulent fluid flow generally results in an increase of shear forces [20]. Bristle motion may cause turbulences as described by Heersink and coworkers and thus shear rates are possibly high enough to stimulate microbial detachment [44].

The amount of entrapped air bubbles increases proportional to the fluid flow [19]. To remove bacteria from a surface the formation of a three-phase boundary between air bubbles, fluid and bacteria is required. Thus, surface tension forces become effective exceeding hydrodynamic shear forces by several orders of magnitude. The efficacy of bacterial detachment is influenced by the amount of gas in the fluid, the velocity and the diameter of the bubbles [22-24]. The visualization of air bubbles in the included studies supports the concept that powered toothbrushes involve passing air-liquid interfaces in biofilm removal although the proportion in detachment forces was not evaluated [27, 44].

In addition, the vibration of toothbrush bristles may enable acoustic energy transfer. The energy transfer to the biofilm is thought to depend on the frequency and amplitude applied [25]. The formation of oscillatory fluid motions and pressure waves may generate additional shear forces on the bacteria. Furthermore, the oscillation of entrapped air 
bubbles is suggested to enhance shear forces by microstreaming and cavitation effects [26]. The extent to which the acoustic energy created by powered toothbrushes contributes to biofilm reduction, however, is unclear.

There may be a more complex interaction if there is intermittent tooth contact resulting in contact and noncontact biofilm removal. For clarity, the present review referred exclusively to noncontact biofilm removal.

\section{Directions for further research}

The data from this review are promising and suggest the possibility of noncontact biofilm removal by the toothbrushes analyzed. However, for future research the following parameter may be considered.

The use of

1. Multispecies biofilm models

2. A flow chamber model

3. Saliva for pellicle formation on a suitable substratum

4. An adjustable toothbrush apparatus, in terms of bristle angulation, distance, and load

5. Clinically relevant brushing protocols, in terms of brushing time, brushing distance, and liquid brushing environment.

Noncontact brushing may have the potential to improve oral hygiene in difficult to access areas, as up to now the clinical effectiveness of different types of powered toothbrushes does not correlate with the results of their respective noncontact biofilm removal capacities in vitro [18]. This conflict needs to be addressed in an appropriate clinical setting. Recently, a review provided a methodological guidance for randomized clinical trials comparing different toothbrushing modes [63]. The authors concluded that future clinical studies may require a longer follow-up, a standardization of indices and clinical relevant thresholds for differences in plaque and gingival health.

\section{Conclusions}

In conclusion, a great heterogeneity in microbial parameter, biofilm formation, and/or brushing protocols exist among the studies included in the review. However, noncontact biofilm removal by powered toothbrushes was a frequent finding. The results of this review can only be applied to the toothbrushes actually tested. Detachment forces, including shear forces, air bubbles interactions, and acoustic energy transfer are suggested to cause noncontact biofilm removal in vitro. Moreover, the clinical gain of noncontact biofilm removal is still unknown. There is no clinical study available, evaluating the extent of noncontact brushing to the observed superiority of powered over manual toothbrushing in terms of plaque reduction. In vitro data should not be translated to the clinical situation.

Conflict of interest The authors declare that there is no conflict of interest. An in vitro analysis of the efficacy of powered toothbrushes is currently under preparation. The latter project is supported in part by an unrestricted grant by the Swiss Society of Dentistry (SSO) with the project number 264-12 (18.06.2012).

\section{References}

1. Socransky SS, Haffajee AD (2002) Dental biofilms: difficult therapeutic targets. Periodontol 28:12-55, 2000

2. Axelsson P, Nystrom B, Lindhe J (2004) The long-term effect of a plaque control program on tooth mortality, caries and periodontal disease in adults. Results after 30 years of maintenance. J Clin Periodontol 31:749-757

3. Ak G, Sepet E, Pinar A, Aren G, Turan N (2005) Reasons for early loss of primary molars. Oral Health Prev Dent 3:113-117

4. Slot DE, Dorfer CE, Van der Weijden GA (2008) The efficacy of interdental brushes on plaque and parameters of periodontal inflammation: a systematic review. Int J Dent Hyg 6:253-264

5. Christou V, Timmerman MF, Van der Velden U, van der Weijden FA (1998) Comparison of different approaches of interdental oral hygiene: interdental brushes versus dental floss. J Periodontol 69:759-764

6. Berchier CE, Slot DE, Haps S, van der Weijden GA (2008) The efficacy of dental floss in addition to a toothbrush on plaque and parameters of gingival inflammation: a systematic review. Int $\mathrm{J}$ Dent Hyg 6:265-279

7. Rosema NA, Hennequin-Hoenderdos NL, Berchier CE, Slot DE, Lyle DM, van der Weijden GA (2011) The effect of different interdental cleaning devices on gingival bleeding. J Int Acad Periodontol 13:2-10

8. Hoenderdos NL, Slot DE, Paraskevas S, Van der Weijden GA (2008) The efficacy of woodsticks on plaque and gingival inflammation: a systematic review. Int J Dent Hyg 6:280-289

9. Van der Weijden FA, Slot DE (2011) Oral hygiene in the prevention of periodontal diseases: the evidence. Periodontol 55:104123,2000

10. Sniehotta FF, Araujo Soares V, Dombrowski SU (2007) Randomized controlled trial of a one-minute intervention changing oral self-care behavior. J Dent Res 86:641-645

11. Konig J, Plagmann HC, Ruhling A, Kocher T (2002) Tooth loss and pocket probing depths in compliant periodontally treated patients: a retrospective analysis. J Clin Periodontol 29:1092-1100

12. Eickholz P, Kaltschmitt J, Berbig J, Reitmeir P, Pretzl B (2008) Tooth loss after active periodontal therapy. 1: patient-related factors for risk, prognosis, and quality of outcome. J Clin Periodontol $35: 165-174$

13. Matuliene G, Studer R, Lang NP, Schmidlin K, Pjetursson BE, Salvi GE, Bragger U, Zwahlen M (2010) Significance of periodontal risk assessment in the recurrence of periodontitis and tooth loss. J Clin Periodontol 37:191-199

14. Leung WK, Ng DK, Jin L, Corbet EF (2006) Tooth loss in treated periodontitis patients responsible for their supportive care arrangements. J Clin Periodontol 33:265-275

15. Emling RC, Yankell SL (1997) The application of sonic technology to oral hygiene: the third generation of powered toothbrushes. J Clin Dent 8:1-3

16. Chilton NW, Didio A, Rothner JT (1962) Comparison of the clinical effectiveness of an electric and a standard toothbrush in normal individuals. J Am Dent Assoc 64:777-782 
17. Robinson PG, Deacon SA, Deery C, Heanue M, Walmsley AD, Worthington HV, Glenny AM, Shaw WC (2005) Manual versus powered toothbrushing for oral health. Cochrane Database Syst Rev CD002281

18. Deacon SA, Glenny AM, Deery C, Robinson PG, Heanue M, Walmsley AD, Shaw WC (2010) Different powered toothbrushes for plaque control and gingival health. Cochrane Database Syst Rev CD004971

19. Sharma PK, Gibcus MJ, van der Mei HC, Busscher HJ (2005) Influence of fluid shear and microbubbles on bacterial detachment from a surface. Appl Environ Microbiol 71:3668-3673

20. Landau LD, Lifshitz EM (1987) Fluid mechanics. Pergamon Press, Oxford

21. Lance M, Bataille J (1991) Turbulence in the liquid phase of a uniform bubbly air-water flow. J Fluid Mech 222:95-118

22. Parini MR, Pitt WG (2005) Removal of oral biofilms by bubbles: the effect of bubble impingement angle and sonic waves. J Am Dent Assoc 136:1688-1693

23. Parini MR, Eggett DL, Pitt WG (2005) Removal of Streptococcus mutans biofilm by bubbles. J Clin Periodontol 32:1151-1156

24. Parini MR, Pitt WG (2006) Dynamic removal of oral biofilms by bubbles. Colloids Surf B Biointerfaces 52:39-46

25. Busscher HJ, Jager D, Finger G, Schaefer N, van der Mei HC (2010) Energy transfer, volumetric expansion, and removal of oral biofilms by non-contact brushing. Eur J Oral Sci 118: $177-182$

26. Pitt WG (2005) Removal of oral biofilm by sonic phenomena. Am J Dent 18:345-352

27. Adams H, Winston MT, Heersink J, Buckingham-Meyer KA, Costerton JW, Stoodley P (2002) Development of a laboratory model to assess the removal of biofilm from interproximal spaces by powered tooth brushing. Am J Dent $15 \mathrm{Spec}$ No. 12B-17B

28. Roberts FA, Hacker BM, Oswald TK, Mourad PD, McInnes C (2010) Evaluation of the use of ultrasound within a power toothbrush to dislodge oral bacteria using an in vitro Streptococcus mutans biofilm model. Am J Dent 23:65-69

29. Schatzle M, Sener B, Schmidlin PR, Imfeld T, Attin T (2010) In vitro tooth cleaning efficacy of electric toothbrushes around brackets. Eur J Orthod 32:481-489

30. Mourad PD, Roberts FA, McInnes C (2007) Synergistic use of ultrasound and sonic motion for removal of dental plaque bacteria. Compend Contin Educ Dent 28:354-358

31. Sander FM, Sander C, Toth M, Sander FG (2006) Dental care during orthodontic treatment with electric toothbrushes. J Orofac Orthop 67:337-345

32. van der Mei HC, Rustema-Abbing M, Bruinsma GM, de Jager M, Gottenbos B, Busscher HJ (2004) Influence of weight on removal of co-adhering bacteria from salivary pellicles by different modes of brushing. Caries Res 38:85-90

33. Yankell SL, Shi X, Emling RC, Bock RT (1999) Subgingival access and artificial plaque removal by a sonic cleaning device. J Clin Dent 10:139-142

34. MacNeill S, Walters DM, Dey A, Glaros AG, Cobb CM (1998) Sonic and mechanical toothbrushes. An in vitro study showing altered microbial surface structures but lack of effect on viability. $\mathbf{J}$ Clin Periodontol 25:988-993

35. Blanco VL, Cobb CM, Williams KB, Manch-Citron JN (1997) In vitro effect of the sensonic toothbrush on treponema denticola. J Clin Periodontol 24:318-323

36. Yankell SL, Emling RC, Shi X (1997) Interproximal access efficacy of Sonicare plus and Braun oral-b ultra compared to a manual toothbrush. J Clin Dent 8:26-29

37. Stanford CM, Srikantha R, Wu CD (1997) Efficacy of the Sonicare toothbrush fluid dynamic action on removal of human supragingival plaque. J Clin Dent 8:10-14
38. Schemehorn BR, Keil JC (1995) The effect of an oscillating/ rotating electric toothbrush and a sonic toothbrush on removal of stain from enamel surfaces. J Clin Dent 6:194-197

39. Stanford CM, Srikantha R, Kirchner HL, Wu CD (2000) Removal of supragingival plaque in an intraoral model by use of the Sonicare toothbrush. J Int Acad Periodontol 2:115-119

40. Hope CK, Wilson M (2002) Comparison of the interproximal plaque removal efficacy of two powered toothbrushes using in vitro oral biofilms. Am J Dent 15 Spec No. 7B-11B

41. Hope CK, Petrie A, Wilson M (2003) In vitro assessment of the plaque-removing ability of hydrodynamic shear forces produced beyond the bristles by 2 electric toothbrushes. J Periodontol 74:1017-1022

42. Hope CK, Wilson M (2003) Effects of dynamic fluid activity from an electric toothbrush on in vitro oral biofilms. J Clin Periodontol 30:624-629

43. Hope CK, Petrie A, Wilson M (2005) Efficacy of removal of sucrose-supplemented interproximal plaque by electric toothbrushes in an in vitro model. Appl Environ Microbiol 71:1114 1116

44. Heersink J, Costerton WJ, Stoodley P (2003) Influence of the Sonicare toothbrush on the structure and thickness of laboratory grown Streptococcus mutans biofilms. Am J Dent 16:7983

45. Wu-Yuan CD, Anderson RD (1994) Ability of the Sonicare electronic toothbrush to generate dynamic fluid activity that removes bacteria. J Clin Dent 5:89-93

46. Busscher HJ, Rustema-Abbing M, Bruinsma GM, de Jager M, Gottenbos B, van der Mei HC (2003) Non-contact removal of coadhering and non-coadhering bacterial pairs from pellicle surfaces by sonic brushing and de novo adhesion. Eur J Oral Sci 111:459-464

47. Yuen AF, Nelson R, Johnson MR, McInnes C, Nguyen HK, Sorensen JA (2004) In vitro evaluation of the efficacy and safety of the intelliclean system: interproximal biofilm removal and dentin substrate wear. Compend Contin Educ Dent $25: 44-50$

48. Brambilla E, Cagetti MG, Belluomo G, Fadini L, Garcia-Godoy F (2006) Effects of sonic energy on monospecific biofilms of cariogenic microorganisms. Am J Dent 19:3-6

49. van der Mei HC, Rustema-Abbing M, Bruinsma GM, Gottenbos B, Busscher HJ (2007) Sequence of oral bacterial co-adhesion and non-contact brushing. J Dent Res 86:421-425

50. Verkaik MJ, Busscher HJ, Rustema-Abbing M, Slomp AM, Abbas F, van der Mei HC (2010) Oral biofilm models for mechanical plaque removal. Clin Oral Investig 14:403-409

51. Hannig C, Hannig M (2009) The oral cavity - a key system to understand substratum-dependent bioadhesion on solid surfaces in man. Clin Oral Investig 13:123-139

52. Bos R, van der Mei HC, Busscher HJ (1999) Physical-chemistry of initial microbial adhesive interaction - its mechanisms and methods of study. FEMS Microbiol Rev 23:179-230

53. Li J, Helmerhorst EJ, Leone CW, Troxler RF, Yaskell T, Haffajee AD, Socransky SS, Oppenheim FG (2004) Identification of early microbial colonizers in human dental biofilm. J Appl Microbiol 97:1311-1318

54. Kolenbrander PE, Andersen RN, Blehert DS, Egland PG, Foster JS, Palmer RJ Jr (2002) Communication among oral bacteria. Microbiol Mol Biol Rev 66:486-505, Table of contents

55. Ahimou F, Semmens MJ, Haugstad G, Novak PJ (2007) Effect of protein, polysaccharide, and oxygen concentration profiles on biofilm cohesiveness. Appl Environ Microbiol 73:2905-2910

56. Palmer RJ Jr, Gordon SM, Cisar JO, Kolenbrander PE (2003) Coaggregation-mediated interactions of streptococci and actinomyces detected in initial human dental plaque. J Bacteriol 185:3400-3409 
57. Paramonova E, Kalmykowa OJ, van der Mei HC, Busscher HJ, Sharma PK (2009) Impact of hydrodynamics on oral biofilm strength. J Dent Res 88:922-926

58. Stoodley P, Cargo R, Rupp CJ, Wilson S, Klapper I (2002) Biofilm material properties as related to shear-induced deformation and detachment phenomena. J Ind Microbiol Biotechnol 29:361-367

59. Lea SC, Khan A, Patanwala HS, Landini G, Walmsley AD (2007) The effects of load and toothpaste on powered toothbrush vibrations. J Dent 35:350-354

60. Otten MP, Busscher HJ, van der Mei HC, van Hoogmoed CG, Abbas F (2011) Acute and substantive action of antimicrobial toothpastes and mouthrinses on oral biofilm in vitro. Eur J Oral Sci 119:151-155
61. Williams K, Rapley K, Haun J, Walters P, Grender J, He T, Biesbrock AR (2010) Benefit of the power component of sonic and rotation-oscillation modes of action for plaque removal using power toothbrushes. Am J Dent 23:60-64

62. Sogi SH, Subbareddy VV, Kiran SN (2002) Contamination of toothbrush at different time intervals and effectiveness of various disinfecting solutions in reducing the contamination of toothbrush. J Indian Soc Pedod Prev Dent 20:81-85

63. Robinson PG, Damien Walmsley A, Heanue M, Deacon S, Deery C, Glenny AM, Worthington H, Shaw W (2006) Quality of trials in a systematic review of powered toothbrushes: suggestions for future clinical trials. J Periodontol 77:1944-1953 